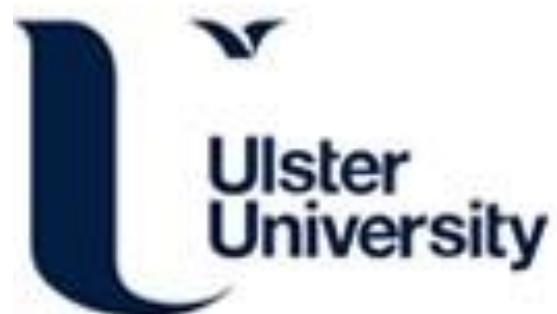

\section{Emission studies of Ba hexaferrite plume produced by a KrF excimer laser}

Papakonstantinou, P., O'Neill, MC., Atkinson, R., Al-Wazzan, R., Morrow, T., \& Salter, IW. (1998). Emission studies of Ba hexaferrite plume produced by a KrF excimer laser. Journal of Applied Physics, 83, 6858-3 pages. https://doi.org/10.1063/1.367657

Link to publication record in Ulster University Research Portal

\section{Published in:}

Journal of Applied Physics

Publication Status:

Published (in print/issue): 01/06/1998

DOI:

10.1063/1.367657

\section{Document Version}

Publisher's PDF, also known as Version of record

\section{General rights}

Copyright for the publications made accessible via Ulster University's Research Portal is retained by the author(s) and / or other copyright owners and it is a condition of accessing these publications that users recognise and abide by the legal requirements associated with these rights.

\section{Take down policy}

The Research Portal is Ulster University's institutional repository that provides access to Ulster's research outputs. Every effort has been made to ensure that content in the Research Portal does not infringe any person's rights, or applicable UK laws. If you discover content in the Research Portal that you believe breaches copyright or violates any law, please contact pure-support@ulster.ac.uk. 
AIP Aappied Physics

\section{Emission studies of Ba-hexaferrite plume produced by a $\mathrm{KrF}$ excimer laser}

P. Papakonstantinou, M. C. O'Neill, R. Atkinson, R. Al-Wazzan, T. Morrow et al.

Citation: J. Appl. Phys. 83, 6858 (1998); doi: 10.1063/1.367657

View online: http://dx.doi.org/10.1063/1.367657

View Table of Contents: http://jap.aip.org/resource/1/JAPIAU/v83/i11

Published by the American Institute of Physics.

\section{Additional information on J. Appl. Phys.}

Journal Homepage: http://jap.aip.org/

Journal Information: http://jap.aip.org/about/about_the_journal

Top downloads: http://jap.aip.org/features/most_downloaded

Information for Authors: http://jap.aip.org/authors

\section{ADVERTISEMENT}

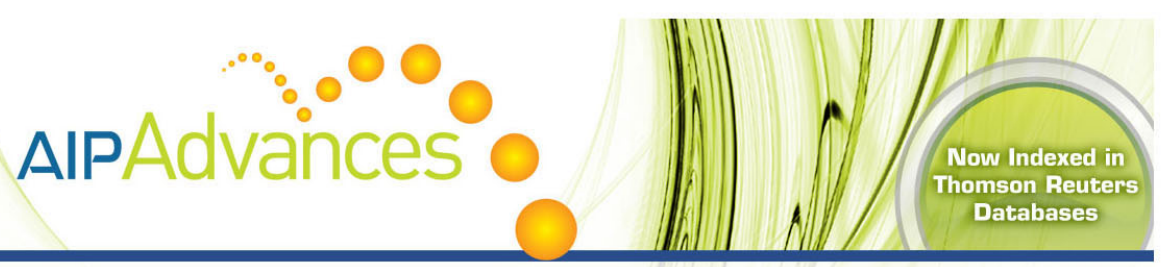

\section{Explore AIP's open access journal: •Rapid publication \\ - Article-level metrics \\ - Post-publication rating and commenting}




\title{
Emission studies of Ba-hexaferrite plume produced by a KrF excimer laser
}

\author{
P. Papakonstantinou, ${ }^{\text {a) }}$ M. C. O'Neill, ${ }^{\text {b) }}$ R. Atkinson, ${ }^{c}$ R. Al-Wazzan, T. Morrow, \\ and I. W. Salter \\ Department of Pure and Applied Physics, The Queen's University of Belfast, BT7 1NN, North Ireland, \\ United Kingdom
}

Optical emission measurements and intensified charge coupled detector images of a plasma generated by the interaction of a $\mathrm{KrF}$ excimer laser with a Ba-ferrite target have been used to study the laser ablation deposition of Ba ferrite thin films. Time integrated spectra were collected as a function of distance above the target surface and as a function of oxygen pressure. Temporal profiles showed that close to the target the plume is insensitive to ambient oxygen pressure and at greater distances a much more pronounced influence is observed. Time resolved images of the overall optical plasma emission clearly demonstrated how the presence of oxygen confines the plasma and enhances its emission. (C) 1998 American Institute of Physics. [S0021-8979(98)29711-8]

\section{INTRODUCTION}

The $M$-type hexaferrites are an important class of materials for microwave, high-density magnetic and magnetooptical (MO) recording technologies. $M$-type $\mathrm{Ba}$ and $\mathrm{Sr}-$ hexaferrite with perpendicular magnetic anisotropy have been previously grown in situ on (001) oriented single crystal substrates of $\mathrm{Al}_{2} \mathrm{O}_{3},{ }^{1}$ yttria stabilized zirconia (YSZ), and $\mathrm{Si}^{2}$, using pulsed laser deposition (PLD). Our earlier studies revealed that hexaferrite films prepared from stoichiometric targets at $840{ }^{\circ} \mathrm{C}$, and $0.1 \mathrm{mbar}$ for a target substrate distance of $30 \mathrm{~mm}$ exhibited the highest degree of crystalline quality and nearly bulk magnetic and magneto-optical properties. At reduced oxygen pressures $(<0.1 \mathrm{mbar})$ the films, which where grown at $840{ }^{\circ} \mathrm{C}$, displayed an enhanced fraction of in plane oriented $\left(c_{\|}\right)$crystallites while at increased oxygen pressures

$(>0.1$ mbar) the surface was populated with outgrowths which also contributed negatively to the perpendicular anisotropy and made the surface rough.

We describe the propagation of excimer laser ablated plasma into background oxygen pressures, used for film growth, as observed by emission spectroscopy and intensified charged coupled detector array (ICCD) photography. The emission characteristics of the plume were correlated with the quality of the Ba-hexaferrite films synthesized by PLD. First, we report on temporally integrated, spatially resolved emission spectra from plasmas along the direction perpendicular to the target surface. The data were collected for plasmas propagating both in vacuum an in an ambient oxygen, from which the composition and state of ionization of the emitting species could be deduced. We have also investigated the effect of oxygen pressure on the spatial and temporal behavior of a number of atomic and ionic species in the plume. Effective species velocities were derived from the time dependent profiles and plasma temperatures were esti-

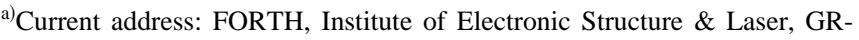
71110 Heraklion, Greece.

${ }^{b)}$ Current address: Seagate Technology, Disc Drive, Springtown, Londonderry, N. Ireland, United Kingdom.

${ }^{c)}$ Electronic mail: Ronald.Atkinson@QUB.AC.UK
}

mated from the integrated line intensity ratios of ionic species. Furthermore, the expansion of the plasma in vacuum and oxygen ambient has been photographed with a gated, intensified CCD array camera system.

\section{EXPERIMENTAL PROCEDURES}

The apparatus used in the present experiments has been described previously. ${ }^{3}$ All measurements were carried out on plasmas produced following $\mathrm{KrF}$ excimer laser $(\lambda$ $=248 \mathrm{~nm}$, full width at half maximum $(\mathrm{FWHM})=20 \mathrm{~ns}) \mathrm{ab}-$ lation, in vacuum and oxygen pressures up to $0.5 \mathrm{mbar}$, at a laser fluence of $2 \mathrm{~J} / \mathrm{cm}^{2}$, with the laser beam incident at $45^{\circ}$ to the rotating $\mathrm{BaFe}_{12} \mathrm{O}_{19}$ target. Temporally integrated emission spectra were recorded by imaging, at a 1:1 magnification, the luminescent plume onto the entrance slit $(25 \mu \mathrm{m}$ wide, $3.7 \mathrm{~mm}$ high) of a compact spectrograph (Oriel Multispec) fitted with a 1024 element photodiode array (Oriel Intaspec). The plasma was viewed perpendicular to its main expansion direction, $z$. The compact spectrograph/diode array assembly was mounted on a micrometer driven transverse slide enabling the spectrograph slit to select light from sections of the plasma adjacent to the target $(z<0.5 \mathrm{~mm})$ to sections $30 \mathrm{~mm}$ along the $z$ axis. The detection system provided wavelength coverage from $350-700 \mathrm{~nm}$ at a spectral resolution of $\sim 1 \mathrm{~nm}$. All recorded spectra were integrated over 100 consecutive laser pulses, accumulated at a repetition rate of $10 \mathrm{~Hz}$.

For temporally resolved measurements a gated intensified 1024 photodiode array and a digital delay generator (DDG) was employed. This detection system had a temporal resolution of $\sim 100 \mathrm{~ns}$ and a spectral resolution of $\sim 1 \mathrm{~nm}$. All spectra data were corrected for a wavelength variation of the intensified photodiode array system.

Temporally resolved two-dimensional (2D) imaging of the total laser-induced plasma emission of a $\mathrm{BaFe}_{12} \mathrm{O}_{19}$ target was performed using a fast gated, ICCD camera system.

\section{RESULTS AND DISCUSSION}

Figure 1 presents a typical spectrum of the temporally integrated plasma emissions observed $2 \mathrm{~mm}$ from the target 


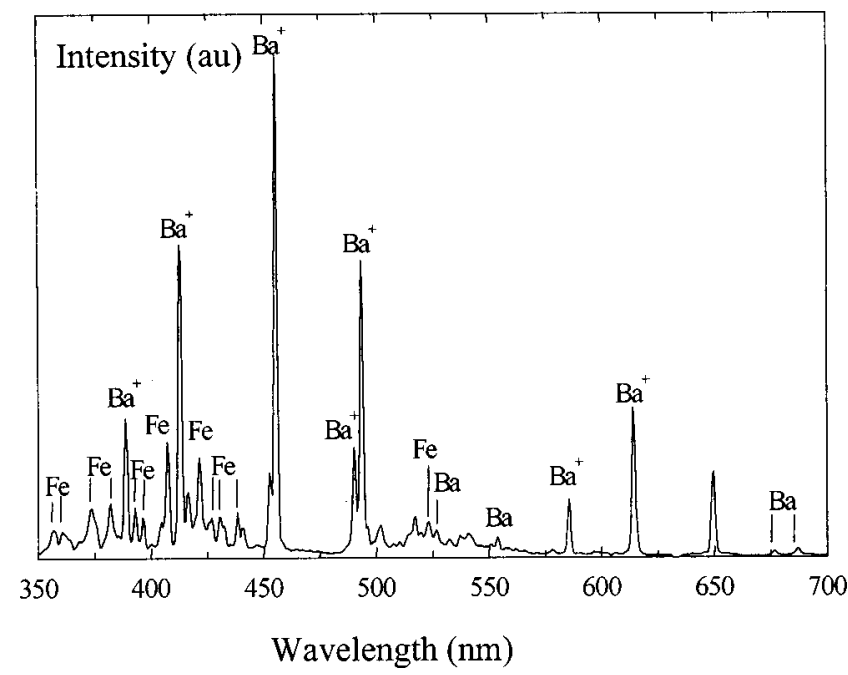

FIG. 1. Temporally integrated emission spectrum recorded at $2 \mathrm{~mm}$ from a $\mathrm{BaFe}_{12} \mathrm{O}_{19}$ target at a base pressure of $10^{-5}$ mbar.

surface at a base pressure of $10^{-5}$ mbar. Only emission lines from $\mathrm{Ba}$ and $\mathrm{Fe}$ neutrals and singly ionized $\mathrm{Ba}$ species were observed. Note that no lines could be assigned to ionized $\mathrm{Fe}$ species in this highly ionized region. This is not surprising since $\mathrm{Fe}^{+}$does not have any strong emission lines in the studied wavelength range; presumably its presence is obscured by strong overlapping emissions emanating from other species.

Furthermore, no bands attributable to diatomic oxide molecules such as $\mathrm{BaO}$ and $\mathrm{FeO}$ could be detected either in vacuum or under oxygen atmospheres along the plasma expansion axis. The reaction of $\mathrm{Ba}$ with $\mathrm{O}_{2}$ to form groundstate $\mathrm{BaO}$ is exothermic by $0.55 \mathrm{eV}$ for low energy $\mathrm{Ba}$ atoms and would occur readily for more energetic $\mathrm{Ba}$ atoms within the plume. ${ }^{4}$ The $\mathrm{BaO}$ formed may undergo collisional excitation but its weak extended emission band system over the range of $450-750 \mathrm{~nm}$ renders identification difficult. The absence of any identifiable strong $\mathrm{BaO}$ in the emission spectra is not therefore unexpected.

Conversely, the formation of excited $\mathrm{FeO}$ from oxidation reactions of atomic $\mathrm{Fe}$ species at the plume oxygen interface is considered unlikely. The reaction of $\mathrm{Fe}$ with $\mathrm{O}_{2}$ is endothermic by $0.92 \mathrm{eV}$ and does not occur for normal collision energies. Some gas phase oxidation might be expected during the earlier energetic phases of plume expansion but the $\mathrm{FeO}$ formed could dissociate rapidly (dissociation energy of $\mathrm{FeO}$ is $4.18 \mathrm{eV}$ ) by collisions with energetic electrons in the high temperature plasma or by single laser photon absorption. It is therefore likely that the ultimate Fe content in the laser deposited films is mainly incident on the growing film in the form of atomic Fe and that appreciable oxidation occurs on the surface.

In the neighborhood of the target surface $(z<0.5 \mathrm{~mm})$, Stark broadened ionic and atomic lines were superimposed on a continuum background. The continuous emission, produced from a hot dense core has been reported ${ }^{5}$ during ablation of several materials.

In vacuum the intensities of all species fell off by a factor greater than 10 , over the first $10 \mathrm{~mm}$. The decline is attributed to a reduction in electron impact excitation of the plasma species as the ion and electron number densities decrease due to free expansion into vacuum.

Introduction of oxygen caused a marked enhancement of the emission at all wavelengths. This is due to confinement of the plasma material within a smaller volume by the higher ambient oxygen pressure, hence enhancing the rate of collisional excitation and the corresponding visible emission. A continuous increase in emission with oxygen pressure was observed in the $0 \leqslant z<20 \mathrm{~mm}$ region. However, for distances of 20 to $30 \mathrm{~mm}$, the radiated emission increased and reached a maximum at 0.1 mbar above which it fell off. Having previously recognized, that the best quality hexaferrite films are obtained at $30 \mathrm{~mm}$ and $0.1 \mathrm{mbar}$, it can be insinuated that the excited state species provide the necessary surface mobility to promote perpendicularly $\left(c_{\perp}\right)$ oriented growth.

It is interesting to examine the nature of the emitting species and effective plasma temperatures along the axis of the plume at 0.1 mbar. Beginning at $2 \mathrm{~mm}$, the main spectral characteristics were similar to those found in vacuum (Fig. 1) i.e., predominant radiation from $\mathrm{Ba}^{+}$with less prominent emissions from neutral $\mathrm{Ba}$ and $\mathrm{Fe}$. However, at distances further away from the target, this dominance of $\mathrm{Ba}^{+}$transitions slowly receded and stronger emissions from $\mathrm{Ba}$ and $\mathrm{Fe}$ neutrals emerged as a result of collisional recombination processes. Assuming local thermodynamic equilibrium conditions, the effective temperature of the plasma, as estimated from the temporally integrated $\mathrm{Ba}^{+}$emission line intensity ratios decreased over the range $1.4-0.8 \mathrm{eV}$ as the contact front of the plume expanded from 2 to $30 \mathrm{~mm}$. The high temperatures $(9500 \mathrm{~K})$ of the species incident on the growing film are thought to facilitate film crystallization and oriented growth.

Further insight into the ablation process was gained by recording the temporal evolution of the $\mathrm{Ba}(553.5 \mathrm{~nm}), \mathrm{Fe}$ $(438.3 \mathrm{~nm})$, and $\mathrm{Ba}^{+}(614.2 \mathrm{~nm})$ emissions at positions 5,10 , and $20 \mathrm{~mm}$ from the target, in different oxygen pressures. The delay time, at which peak radiation was attained, yielded straightforwardly the most probable front axial velocity $v_{z}$. The results indicated that at small distances from the target surface $(z=5 \mathrm{~mm})$, the $\mathrm{Ba}^{+}$species outnumbered the $\mathrm{Ba}$ and Fe neutral population in agreement with the time integrated data. Moreover, the intense ion emission front was observed in advance of the corresponding neutral front by $10 \%-20 \%$. Increasing the oxygen pressure up to 0.5 mbar caused an increase in the emission intensities and a minor shift in the corresponding temporal profiles towards greater delay times. It appears, that the dense plasma expands virtually unhindered by the background oxygen at this region. The explanation for the nondependence of the species velocity on the oxygen pressure is to be found on the mass of the ablated products which is large compared to that of the background gas, set in motion by the plume. ${ }^{6}$

Increase in oxygen pressure had a more pronounced influence on the temporal profiles at greater distances from the target. Figure 2 shows the $\mathrm{Fe}(438.3 \mathrm{~nm})$ time traces at 20 $\mathrm{mm}$. Evidently the emission maximum is increasingly delayed by an increase in oxygen pressure which implies that the plasma expansion is slowed by the higher oxygen pres- 


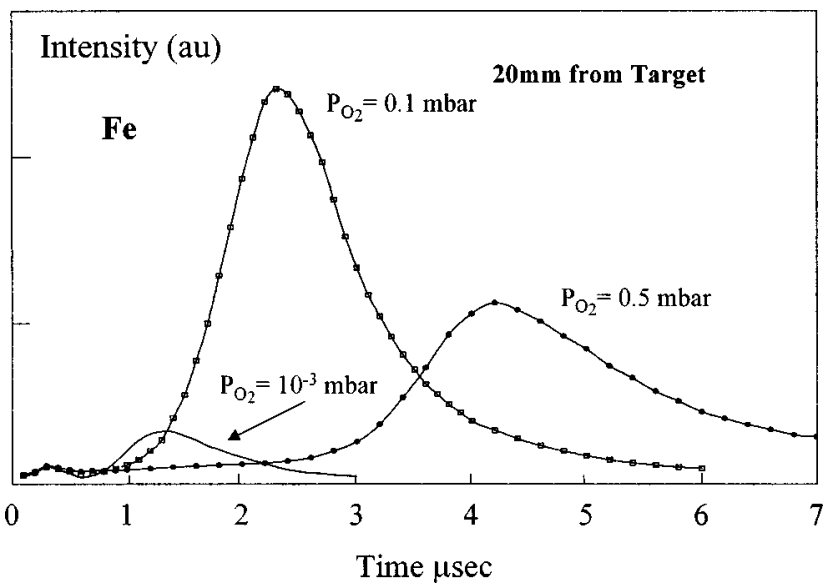

FIG. 2. Temporally resolved emission profiles of Fe recorded $20 \mathrm{~mm}$ from the target, in $10^{-5}, 0.1$, and 0.5 mbar oxygen.

sures. Moreover, comparable maximum velocities $\left(v_{z}\right)$ were obtained for the emission fronts of all the species $(\sim 8.4$ $\times 10^{5} \mathrm{~cm} / \mathrm{s}$ at $0.1 \mathrm{mbar}$ and $\sim 4.6 \times 10^{5} \mathrm{~cm} / \mathrm{s}$ at $0.5 \mathrm{mbar}$ ). A closer inspection of the temporal profiles recorded at $20 \mathrm{~mm}$ revealed a fast and slow component, the latter being eminently intensified with oxygen pressure.

At 0.5 mbar the plasma front was cooled to such an extent that a decrease in the peak emission was observed at the location of $20 \mathrm{~mm}$ (Fig. 2). It is apparent that a further decrease in the peak emission is expected at the longer distance of $30 \mathrm{~mm}$ for the same oxygen pressure. At $0.5 \mathrm{mbar}$ the luminous plume length is smaller than the targetsubstrate distance of $30 \mathrm{~mm}$ and mainly thermalized nonluminous species, transported by diffusion, reach the substrate. The low kinetic energies of the species, together with changes from the stoichiometric arrival cation ratio, are responsible for the presence of misaligned grains and/or foreign phase in the films grown at pressures much higher than 0.1 mbar. $^{1}$ Nevertheless, optimum crystalline and morphological properties could be obtained for a target substrate distance of about $30 \mathrm{~mm}$ at a pressure of $0.1 \mathrm{mbar}$, i.e., for a substrate position within the end of the fully expanded plume.

In Fig. 3 are shown 2D images depicting expanding visible $\mathrm{Ba}$ ferrite plume in vacuum and $0.1 \mathrm{mbar} 1$ and $2 \mu \mathrm{s}$ after the laser impact. It is clearly shown that the background oxygen pressure confines the plasma slows its expansion and enhances the emission particularly at its expansion front. The bright luminance at the expansion front, is correlated principally with the delayed intense peaks of Fig. 2 .

A qualitative picture of the plasma plume dynamics emerges from these spectroscopic results. In vacuum fast "hot" highly ionized material expands rapidly in essentially a free collisionless expansion, strongly forward directed ( $v_{z}$ $\sim 6.6 \times 10^{6} \mathrm{~cm} / \mathrm{s}$ ), leaving behind it, cooler, slower, mainly neutral material. In an oxygen atmosphere, the fast components at the contact front are progressively slowed down re-

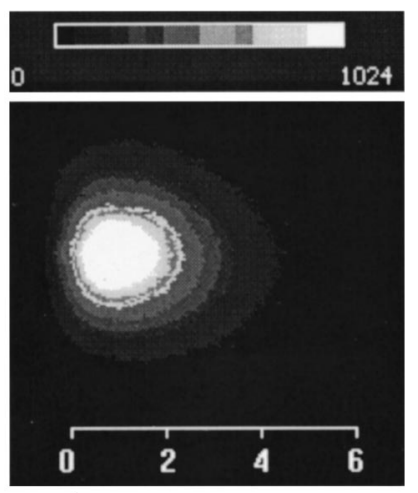

a) $1 \mu_{\mathrm{s}}$

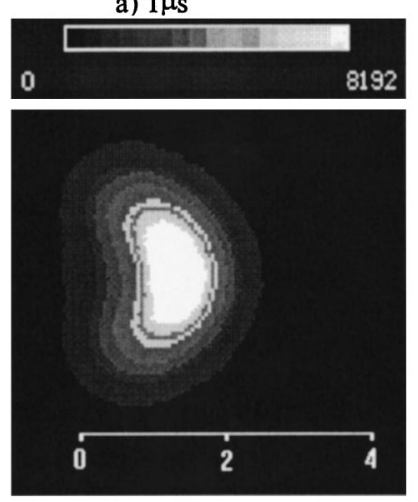

c) $1 \mu \mathrm{s}$

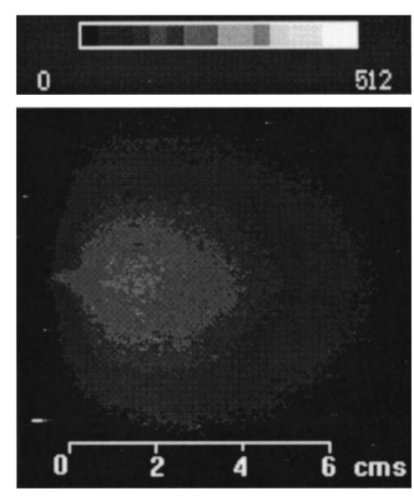

b) $2 \mu_{\mathrm{S}}$
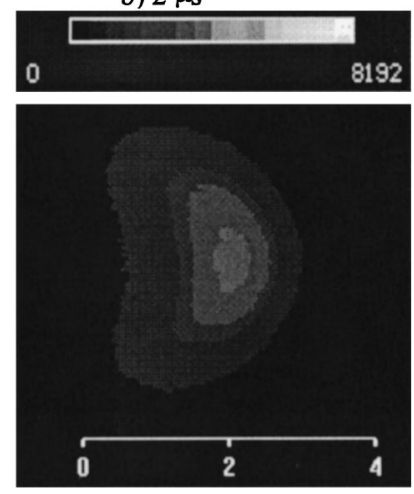

d) $2 \mu_{\mathrm{s}}$
FIG. 3. ICCD images of the visible plasma emission recorded 1 and $2 \mu \mathrm{s}$ after laser impact upon a $\mathrm{BaFe}_{12} \mathrm{O}_{19}$ target in an oxygen pressure of $10^{-5}$ (a) and (b) and 0.1 (c) and (d) mbar.

sulting in collisional redistribution of high $z$ directed velocities into $x$ and $y$ directions ${ }^{7}$ producing a more homogeneous plasma with an equilibrated temperature smaller than $1 \mathrm{eV}$.

\section{CONCLUSIONS}

Temporal emission profiles and time resolved ICCD optical images of the plasma clearly demonstrate, how increasing the oxygen pressure confines the plasma, slows its expansion and enhances the emission particularly at its expanding front. It is concluded that the role of oxygen pressure is not only to supply the oxygen constituent to the film but also to slow down the highly energetic species which otherwise will cause damage to the deposited layer.

${ }^{1}$ P. Papakonstantinou, M. O'Neill, R. Atkinson, I. W. Salter, and R. Gerber, J. Magn. Magn. Mater. 152, 401 (1996).

${ }^{2}$ P. Papakonstantinou, R. Atkinson, I. W. Salter, and R. Gerber, J. Magn. Soc. Jpn. 19, 177 (1995).

${ }^{3}$ A. H. El-Astal, S. Ikram, T. Morrow, W. G. Graham, and D. G. Walmsley, J. Appl. Phys. 77, 6572 (1995).

${ }^{4}$ A. H. El-Astal, T. Morrow, W. G. Graham, and D. G. Walmsley, Supercond. Sci. Technol. 8, 529 (1995).

${ }^{5}$ W. A. Weimer, Appl. Phys. Lett. 52, 2171 (1988).

${ }^{6}$ D. B. Geohegan, in Pulsed Laser Deposition of Thin films, edited D. B. Chrisey and G. K. Hubler (Wiley, New York, 1994), p. 115.

${ }^{7}$ R. A. Al-Wazzan, J. M. Hendron, and T. Morrow, Appl. Surf. Sci. 96-98, 170 (1996). 